\title{
Lung function and aerobic capacity in adult patients following modified Fontan procedure
} P M Fredriksen, J Therrien, G Veldtman, M A Warsi, P Liu, S Siu, W Williams, J Granton,
G Webb

\begin{abstract}
Objective-To examine cardiopulmonary performance in 52 adult patients with a Fontan circulation.

Design-Retrospective cohort study. Values of maximum oxygen uptake $\left(\mathrm{Vo}_{2} \mathrm{max}\right)$, maximum heart rate (HRmax), forced vital capacity (FVC), and forced expiratory volume in one second $\left(\mathrm{FEV}_{1}\right)$ were compared with predictive values for different age groups. Patients were further subdivided into those with a pulmonary artery connection (RA-PA) or right atrium to right ventricle conduit (RA-RV).

Results-At late follow up (median 10 years, range 1 to 26 years), patients with Fontan circulation had greatly diminished $\mathrm{VO}_{2} \mathrm{max}, \mathrm{HRmax}, \mathrm{FVC}$, and $\mathrm{FEV}_{1}$ compared with predicted values. Early age at surgery had a positive impact on aerobic capacity. The $\mathrm{FEV}_{1}: \mathrm{FVC}$ ratio indicated restrictive lung function. No differences were found with respect to any variable between patients with RA-PA connections and those with RA-RV connections.

Conclusions-Patients with a Fontan circulation have greatly diminished values of aerobic capacity and a restrictive pattern of lung function. Patients with an early surgical procedure obtained higher values of $\mathrm{VO}_{2}$ max. The theoretical benefits of including the right ventricle in a Fontan circulation were not apparent.
\end{abstract}

(Heart 2001;85:295-299)

Keywords: congenital heart disease; exercise test; lung function; aerobic capacity

The natural history of complex cyanotic heart disease was radically changed by the introduction of venous shunt procedures. In tricuspid atresia the mortality in the presence of infundibular pulmonary stenosis used to be $90 \%$ by the end of the first year, ${ }^{1}$ and in the absence of pulmonary stenosis similar mortality occurred by the 10 th year of life. Glenn and Patino first described the theory behind the bypass of the right ventricle ${ }^{2}$ and later published a clinical report based on this theory. ${ }^{3}$ Fontan and Baudet described what has now become known as the classical Fontan procedure in $1971 .^{4}$ This improved the longevity of patients with tricuspid atresia. ${ }^{5}$ After this description several modifications have emerged, and the procedure has also now been applied to a wider spectrum of congenital heart defects. The atriopulmonary anastomosis was advocated by Kreuzer and associates and later by de Leval and colleagues, who described the lateral tunnel procedure.$^{67}$ More recently the extracardiac tunnel has been described. ${ }^{8}$

The right atrium to right ventricle conduit (RA-RV) was first reported by Björck and colleagues in $1979 .{ }^{9}$ The role of the right ventricle in the Fontan circulation has been a subject of controversy. Pulsatile blood flow potentially increases cardiac output during exercise and is therefore thought to increase functional capacity. ${ }^{10}$ Furthermore the circulation is also driven by two pumps and is therefore less dependent on the systemic ventricle. However, complications with this modification are well recognised. Conduit failure develops with time and replacement is required. ${ }^{11}$ Obstruction may also occur as a result of compression by the anterior thoracic wall. The physiological ben- efit of this modification has not been demonstrated in an adult cohort.

With improved survival beyond childhood, increasing numbers of patients with the Fontan circulation are being managed at adult congenital heart disease centres. ${ }^{12}{ }^{13}$ They have significant morbidity in the form of atrial arrhythmias $(20 \%$ by five years), protein losing enteropathy, and severely diminished exercise capacity. ${ }^{5}{ }^{11}{ }_{14-22}$ Long term survival is compromised, with only a $60 \% 10$ year survival. ${ }^{5}$

Some questions remain unanswered in this patient population-for example, what is the role of respiratory function in aerobic capacity and what is the aerobic ability at late follow up in this group? It was our aim in the present study to compare lung function and dynamic exercise performance between healthy adults and patients with the Fontan circulation. In addition, we aimed to investigate the influence of age at surgery and to define differences in exercise responses between patients with an RA-PA connection and those with an RA-RV conduit.

\section{Methods}

PATIENT POPULATION

At the Hospital for Sick Children and Toronto General Hospital, 565 patients have undergone a modified Fontan procedure. At the time of study, 223 of these were expected to be 18 years of age or older. However, this group of patients had an early mortality (within three months after surgery) of $16 \%$ (36 patients), and a late mortality (more than five years after surgery) of $6 \%$ (14 patients) before the age of 18. Thus only 173 patients reached the age of 
Table 1 Descriptive data for the Fontan patients

\begin{tabular}{llllr}
\hline Variable & $\begin{array}{l}\text { All Fontan } \\
(n=52)\end{array}$ & $\begin{array}{l}\text { Male } \\
(n=27)\end{array}$ & $\begin{array}{l}\text { Female } \\
(n=25)\end{array}$ & $p$ Value \\
\hline Age at test (years) & $26.5(18-45)$ & $26(19-45)$ & $27(18-37)$ & 0.582 \\
Weight (kg) & $64(41-100)$ & $69(51-100)$ & $60(41-75)$ & $<0.001$ \\
Height $(\mathrm{cm})$ & $170(146-188)$ & $175(157-188)$ & $163(146-173)$ & $<0.0001$ \\
Age at surgery (years) & $17.5(5-36)$ & $17.5(5-36)$ & $17(7-29)$ & 0.712 \\
Years since surgery & $10(1-26)$ & $10(1-26)$ & $10(1-21)$ & 0.865 \\
\hline
\end{tabular}

Values are median (range)

$\star$ Based on 49 patients.

The $\mathrm{p}$ values are given for differences between the sexes.

$18(77.5 \%)$. The mortality rate after the age of 18 was $8 \%$ (17 patients).

Of the 156 patients still alive at the time of this study, $131(83 \%)$ are being followed at the University of Toronto Congenital Cardiac Centre for Adults (TCCCA). Of these 131 patients, $52(40 \%)$-identified from the cardiopulmonary database-had lung function and exercise tests over a 10 year period (1989 to 1999) (table 1). These patients underwent the Fontan procedure between 1977 and 1994. The reason for not including all the patients was that they are not all being followed actively at TCCCA, and not all had attended for exercise testing at the time the data were analysed.

Underlying diagnoses include tricuspid atresia ( 25 patients), univentricular connection (11 patients), and transposition of the great arteries (eight patients with simple complete transposition and eight with congenitally corrected transposition). Two different surgical procedures were used (RA-PA in 37 patients and RA-RV in 15 patients). Twenty nine of the patients have been reported in a previous paper. ${ }^{11}$

\section{CARDIOPULMONARY TESTS}

Cardiopulmonary tests were performed at Toronto General Hospital on a cycle ergometer (Elema, Sweden). Continuous measurements of expired gas values were analysed every 30 seconds (Amtech $\mathrm{Vo}_{2}$ oxygen analyser S-3A/I, Pittsburg, Pennsylvania, USA). The analyser was calibrated before tests using known values of oxygen and carbon dioxide. During the test, measurements of blood pressure, heart rate, ventilation (VE), and oxygen saturation $\left(\mathrm{SaO}_{2}\right)$ were made continuously. All patients started at $20 \mathrm{~W}$ for warm up during the first minute. Workload was increased by $20 \mathrm{~W}$ every two minutes to the point of fatigue. The American College of Sport Medicine (ACSM) guidelines for ending an exercise test were used. ${ }^{23}$ Before the exercise tests, spirometry (SensorMedics, USA) was conducted according to American Thoracic Society standards, with measurements of forced expiratory volume in one second $\left(\mathrm{FEV}_{1}\right)$ and forced vital capacity (FVC). ${ }^{24} 25$

The results of $\mathrm{VO}_{2} \max$ from the Fontan patients were compared with a healthy population in Canada over different age groups. ${ }^{26}$ Results of $\mathrm{FEV}_{1}$ and FVC were compared with predicted values calculated from equations reported by Jones. ${ }^{25}$

\section{STATISTICS}

Data were analysed using SPSS 9.0 for Windows. Median values with range were used

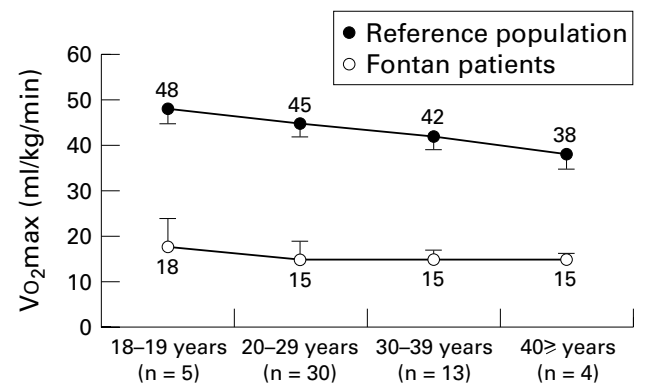

Figure 1 The values of maximum oxygen consumption

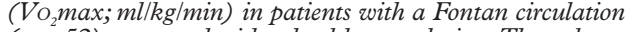
( $n=52$ ) compared with a healthy population. The values for patients are given as median and 75th centile for both sexes in order to compare them with the reference population (median and 25th centile).

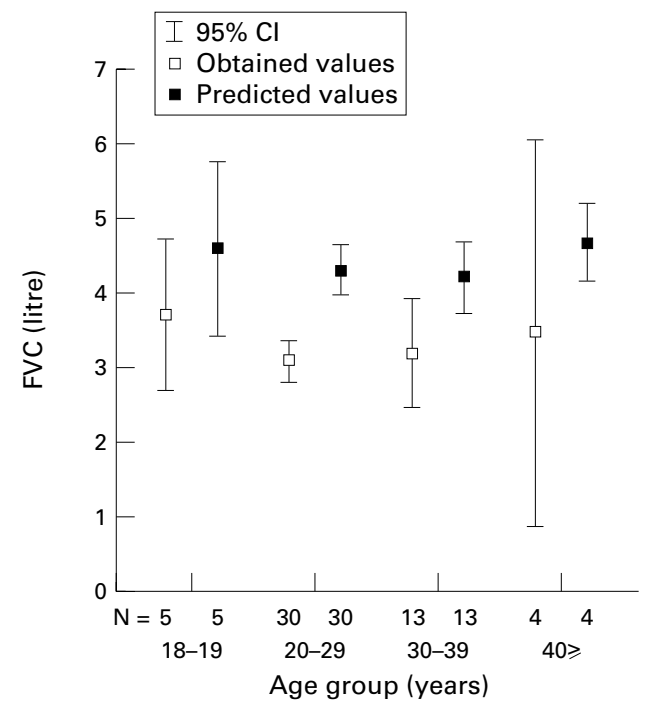

Figure 2 Obtained and predicted mean values (with 95\% confidence intervals) of forced expiratory capacity (FVC) in all patients $(n=52)$ with a modified Fontan circulation.

descriptively and to compare $\mathrm{VO}_{2} \max$ in patients with Fontan circulation with a healthy population. Differences between Fontan patients and predicted values with respect to FVC and $\mathrm{FEV}_{1}$ were analysed with the MannWhitney test, and analysis over different age groups was done by analysis of variance. Multivariate linear regression modelling (stepwise backward elimination selection procedure) was used to examine the relation between age at surgery, age at test, years since surgery, type of surgery, sex, and outcome variables of $\mathrm{Vo}_{2} \max$, maximum heart rate (HRmax), maximum ventilation (VEmax), FVC, and $\mathrm{FEV}_{1}$. If two independent variables were closely correlated $(r>0.70)$, only the variable with the strongest correlation with the outcome of interest was entered into the multivariate model. Mean values for RA-RV $v$ RA-PA were compared using the two sample Student $t$ test. A probability value of $p<0.05$ was regarded as significant.

\section{Results}

$\mathrm{VO}_{2} \max (\mathrm{ml} / \mathrm{kg} / \mathrm{min})$ was severely diminished in the Fontan patients compared with a healthy population, their achievement being on average $35.7 \%$ (range $33-39 \%$ ) of the reference values 


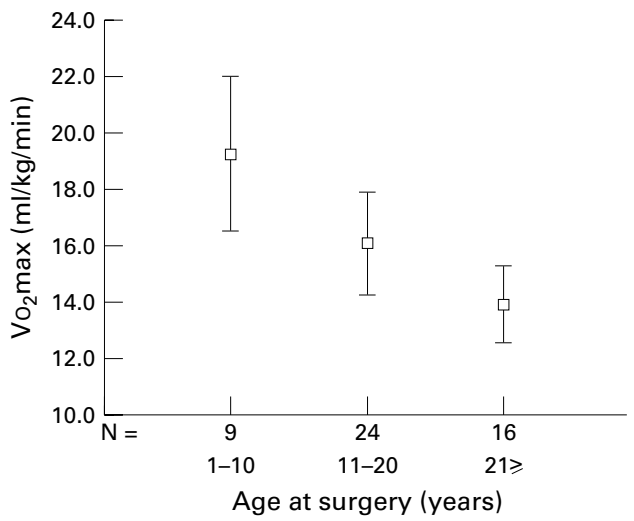

Figure 3 The effect of age at time of Fontan surgery on maximum oxygen consumption ( $\mathrm{VO}_{2}$ max; $\mathrm{ml} / \mathrm{kg} / \mathrm{min}$ ). The data are based on 49 patients (age at surgery was not recorded in three patients).

(fig 1). In addition, both VEmax and HRmax were reduced compared with normal values. The mean oxygen saturation was also decreased.

The mean values for FVC (fig 2) and $\mathrm{FEV}_{1}$ were reduced $(p<0.0001)$ compared with predicted values. However, no differences over age groups were found (FVC, $\mathrm{p}=0.821$; $\mathrm{FEV}_{1}, \mathrm{p}=0.632$ ). Determination of the ratio $\mathrm{FEV}_{1}: \mathrm{FVC}$ showed that $58 \%$ of the patients had a restrictive pattern.

In the univariate model a negative correlation was found when $\mathrm{VO}_{2} \max$ was analysed against both age at surgery $(r=-0.413$, $\mathrm{p}=0.003)$ and age at test $(r=-0.351$, $\mathrm{p}=0.012)$. In the multivariate model, how-

Table 2 Results of the spirometry and cardiopulmonary test show for the whole Fontan sample and divided into sexes

\begin{tabular}{|c|c|c|c|c|}
\hline Variable & All Fontan & Male & Female & p Value \\
\hline $\mathrm{VO}_{2} \max (\mathrm{ml} / \mathrm{kg} / \mathrm{min})$ & $15.9(4.0)$ & $17.1(3.79)$ & $14.5(3.81)$ & 0.015 \\
\hline $\mathrm{Vo}_{2} \max (\mathrm{ml} / \mathrm{min})$ & $1043(372)$ & $1210(374)$ & $855(271)$ & $<0.0001$ \\
\hline Maximum ventilation $(1 / \mathrm{min})$ & $49.3(14.2)$ & $55.1(15.3)$ & $42.7(9.7)$ & $<0.001$ \\
\hline Maximum heart rate (beats/min) & $139(25)$ & $140(26)$ & $138(24)$ & 0.688 \\
\hline $\mathrm{O}_{2}$ saturation $(\%)^{\star}$ & $87(5)$ & $88(6)$ & $87(4)$ & 0.881 \\
\hline $\begin{array}{l}\text { Maximum systolic blood pressure } \\
(\mathrm{mm} \mathrm{Hg})\end{array}$ & $150(30)$ & $160(29)$ & $140(28)$ & 0.034 \\
\hline $\begin{array}{l}\text { Maximum diastolic blood pressure } \\
(\mathrm{mm} \mathrm{Hg})\end{array}$ & 77 (18) & $79(13)$ & $75(22)$ & 0.526 \\
\hline FVC (litre) & $3.20(0.96)$ & $3.65(1.07)$ & $2.72(0.53)$ & $<0.0001$ \\
\hline FVC (\% predicted) & $77(16)$ & $78(19)$ & $76(11)$ & 0.801 \\
\hline $\mathrm{FEV}_{1}$ (litre) & $2.62(0.70)$ & $2.95(0.76)$ & $2.27(0.41)$ & $<0.0001$ \\
\hline $\mathrm{FEV}_{1}(\%$ predicted $)$ & $80(16)$ & $80(17)$ & $80(11)$ & 0.246 \\
\hline
\end{tabular}

Values are mean (SD).

*Based on 24 patients.

The $\mathrm{p}$ values are given for differences between the sexes.

$\mathrm{FEV}_{1}$, forced expiratory volume in one second; $\mathrm{FVC}$, forced vital capacity; $\mathrm{Vo}_{2} \mathrm{max}$, maximum oxygen uptake.

Table 3 Descriptive and exercise data for patients with right atrium to pulmonary artery connection $(R A-P A)$ and right atrium to right ventricular conduit $(R A-R V)$

\begin{tabular}{llll}
\hline Variable & $R A-P A(n=37)$ & $R A-R V(n=15)$ & $p$ Value \\
\hline Sex (male) & $21(57 \%)$ & $6(40 \%)$ & \\
Age at test (years) & $26(18-45)$ & $29(18-36)$ & 0.744 \\
Weight (kg) & $65(42-100)$ & $61(41-80)$ & 0.435 \\
Height (cm) & $170(146-188)$ & $168(158-185)$ & 0.539 \\
Age at surgery (years) & $18(7-36)$ & $15(5-27)$ & 0.100 \\
Years since surgery & $9(1-26)$ & $12(1-21)$ & 0.038 \\
Vo $_{2}$ max (ml/kg/min) & $15.5(8-25)$ & $15.0(11-23)$ & 0.686 \\
Maximum ventilation (1/min) $_{\text {Maximum heart rate (beats/min) }}$ & $19(24-100)$ & $47(29-63)$ & 0.494 \\
Systolic blood pressure (mm Hg) & $137(96-194)$ & $139(86-179)$ & 0.645 \\
Diastolic blood pressure (mm Hg) & $81(18)$ & $145(27)$ & 0.470 \\
FVC (litre) & $3.1(1.2-5.1)$ & $68(14)$ & 0.037 \\
FEV $_{1}$ (litre) & $2.6(0.9-4.1)$ & $2.1(2.5-5.5)$ & 0.825 \\
\hline
\end{tabular}

Values are mean (range), mean (SD), or $\mathrm{n}(\%)$. ever, age at surgery was the single most important predictor of $\mathrm{VO}_{2} \mathrm{max}$ in patients with the Fontan circulation $(\mathrm{p}<0.001)$. The younger the patients were at surgery, the better was their aerobic capacity (fig 3 ). Sex also had an effect on $\mathrm{VO}_{2} \max (\mathrm{p}=0.003)$ : male patients achieved higher values, as shown in table 2 . With regard to FVC, $\mathrm{FEV}_{1}$, and VEmax, only sex had a significant impact on the results, male patients achieving higher values. No effect of time since repair was found. None of the variables examined was found to influence HRmax.

Comparisons between patients with an RA-PA connection and those with an RA-RV connection are given in table 3 . The only variable that differed significantly between these two groups was maximum diastolic blood pressure. However, in neither case did the mean diastolic blood pressure differ from normal control values.

\section{Discussion}

In this retrospective analysis, results of exercise tests in 52 patients late after a Fontan repair operation were compared with values obtained in a healthy population. The patients were subdivided into those given a right atrium to pulmonary artery connection and those with a right atrium to right ventricle conduit. The main findings were that patients with a Fontan circulation have impaired lung function and diminished aerobic capacity. Age at surgery had a positive effect on aerobic capacity, as patients with an early surgical procedure obtained higher values of $\mathrm{VO}_{2} \mathrm{max}$. No differences were found between patients with an RA-PA connection and those with an RA-RV conduit.

AEROBIC CAPACITY OVER AGE GROUPS

Our patents had diminished aerobic capacity, in agreement with previous studies of adults, adolescents, and children with a Fontan circulation. ${ }^{11}{ }^{14-21} \mathrm{VO}_{2} \max$ varied between $33 \%$ and $39 \%$ of the reference population. A possible reason for this may be an inability to increase cardiac output. ${ }^{11} 21$ Another could be reduced physical activity level in the patients compared with the reference population. The reference values used in the present study are based on 23000 healthy Canadians, who may have a higher daily activity level than other reference populations in North America. The severely diminished maximum ventilation compared with predicted values may also contribute to the diminished aerobic capacity.

Values of $\mathrm{VO}_{2} \mathrm{max}$ in our study were lower than those reported by other investigators. ${ }^{27}$ This may be because the patients in our cohort were older, or because our study did not include patients with any of the newer haemodynamic modifications of the Fontan procedure. Interestingly, the Fontan patients did not show any decline in aerobic capacity with age, as healthy subjects do. Other investigators have observed the same phenomenon. ${ }^{18}$ A possible reason for this could be that the severely reduced cardiac output masks the effect of age. However, the duration of follow up in our study 
might have been insufficient to detect age related changes.

LUNG FUNCTION

The values of FVC and $\mathrm{FEV}_{1}$ were impaired in Fontan patients. The reasons for this are not entirely clear. The $\mathrm{FEV}_{1}: \mathrm{FVC}$ ratio indicated a restrictive pattern. Diaphragmatic palsy following surgery, respiratory muscle weakness, or a restrictive thoracic cage could be contributing factors.

HEART RATE

We found that maximum heart rates were decreased compared with the reference population. The majority of studies have reported a low heart rate response to exercise in the Fontan population, but the values in our study were even lower than those reported by others. ${ }^{1822} 28$ This probably reflects the older mean age of our cohort. It is generally believed that abnormal autonomic control, dysfunction of the sinus node, and other factors contribute to the abnormal response..$^{1522}$

As suggested by others, the correlation between $\mathrm{VO}_{2}$ max and HRmax did not achieve significance $(r=0.269, \mathrm{p}=0.062)$, indicating that HRmax was not a major determinant of aerobic capacity. ${ }^{29}$ The reason for this may be that an increased stroke volume during exercise compensates for the decreased heart rate. ${ }^{29}$ However, an increase in stroke volume is not sufficient to achieve an adequate cardiac output during exercise, which explains the diminished values of $\mathrm{VO}_{2} \mathrm{max}$ in the present study.

VARIABLES PREDICTING $\mathrm{VO}_{2} \mathrm{MAX}$

In this study the linear regression model showed that male subjects achieved higher $\mathrm{VO}_{2} \mathrm{max}$ values than female subjects, in agreement with others. ${ }^{22}$ Age at surgery, regardless of the type of surgery, was the most important factor in determining $\mathrm{VO}_{2} \max$. The younger the patients were at the time of surgery the better was their $\mathrm{VO}_{2} \max$ at late follow up. Early surgery may therefore be preferable, and this is currently the most common approach in congenital heart disease centres worldwide.

$\mathrm{RA}-\mathrm{RV} v \mathrm{RA}-\mathrm{PA}$

We found no significant differences between patients with an RA-RV conduit and an RA-PA connection, as observed by others. ${ }^{10}$ Weipert and colleagues suggested that bulging of the right ventricle into the left ventricle impaired left ventricular diastolic compliance and increased the left ventricular filling pressure. ${ }^{14}$ However, other investigators have found low diastolic right ventricular pressures and have observed that the right ventricle is often hypoplastic and considerably smaller than the left ventricle. ${ }^{10} 30$

The diminished aerobic capacity in RA-RV patients is most likely to be caused by the same factors that result in decreased $\mathrm{VO}_{2} \mathrm{max}$ in patients with RA-PA. A reduced systemic ventricular filling limited by the poor pulmonary venous return has been suggested as the major determinant of exercise capacity in Fontan patients. ${ }^{19}$ Bull and colleagues found that the right ventricle did not perform any positive work when included in the pulmonary circulation. ${ }^{30}$ It is possible therefore that the pumping capacity of the right ventricle is so poor that it does not contribute in any great extent to systolic function, as suggested by others. ${ }^{31}$ Despite this, Bull and colleagues suggested that a conduit should be included when possible. ${ }^{30}$

In view of the lack of positive effect on $\mathrm{VO}_{2}$ max we believe that the theoretical physiological benefits of including the right ventricle in the Fontan circulation may be offset by the long term complications that result in failure of the right ventricular conduit, such as compression against the anterior chest wall, conduit calcification, and stenosis or regurgitation requiring replacement. ${ }^{31}$

LIMITATIONS OF THE STUDY

This study is limited by the follow up constraints inherent in caring for adults with congenital heart disease. Many of our patients reside outside Toronto, and those who are well may be less interested in returning to our centre for cardiopulmonary testing. Our 52 patients may therefore represent a biased sample with more medical problems and a poorer exercise capacity. In addition, no information was available on smoking habits in the study sample.

\section{CLINICAL IMPLICATIONS}

The main clinical implication is that patients who had surgery at a younger age have a better aerobic capacity than those who had surgery at an older age. In addition, the use of the right ventricle appears to have no impact on aerobic capacity and it may therefore be omitted in the Fontan circulation.

\section{CONCLUSIONS}

Adult patients late after the Fontan procedure have greatly reduced aerobic capacity compared with healthy subjects. Possible explanations are reduced chronotropic response, decreased systemic ventricular preload, and diminished ventilatory capacity. A pronounced restrictive respiratory pattern was observed, which may contribute to the diminished aerobic capacity. Age at surgery has a positive effect on aerobic capacity, as patients who had early surgery obtained higher values of $\mathrm{VO}_{2} \max$. Though in theory it should be beneficial to include the right ventricle in the Fontan circulation, we found no evidence in support of this in our study.

PMF was supported by The Norwegian Association for Children with Congenital Heart Disorders (FFHB), the Norwegian Lung and Heart Association, and by the National Foundation of Public Health in Norway. GV was supported by the National Heart Research Fund, UK.

1 Campbell $M$. Tricuspid atresia and its prognosis with and without surgical treatment. Br Heart f 1961;23:699-710.

2 Glenn WWL, Patino JF. Circulatory by-pass of the right heart. I. Preliminary observations on the direct delivery of heart. 1. Preliminary observations on the direct delivery of vena caval blood into the pulmonary arterial circulation. Azygous vein-pulmonary artery shunt. Yale f Biol Med
1954;27:147-51.

3 Glenn WWL. Circulatory bypass of the right side of the pulmonary artery-report of clinical application. N Engl $\mathcal{F}$ Med 1958;259:117-20. 
4 Fontan F, Baudet E. Surgical repair of tricuspid atresia. Thorax 1971;26:240-8.

5 Driscoll DJ, Offord KP, Feldt RH, et al. Five- to fifteen-year follow-up after Fontan operation. Circulation 1992;85:46996.

6 Kreutzer G, Galindez E, Bono H, et al. An operation for the correction of tricuspid atresia. F Thorac Cardiovasc Surg 1973;66:613-21.

7 de Leval MR, Kilner P, Gewillig M, et al. Total cavopulmonary connection: a logical alternative to atriopulmonary connection for complex Fontan operations. Experimental studies and early clinical experience. $\mathcal{F}$ Thorac Cardiovasc Surg 1988;96:682-95.

8 Marcelletti C, Corno A, Giannico S, et al. Inferior vena cava-pulmonary artery extracardiac conduit. A new form of right heart bypass. F Thorac Cardiovasc Surg 1990;100: 228-32.

9 Bjork VO, Olin CL, Bjarke BB, et al. Right atrial-right ventricular anastomosis for correction of tricuspid atresia. $\mathcal{f}$ Thorac Cardiovasc Surg 1979;77:452-8.

10 Lee CN, Schaff HV, Danielson GK, et al. Comparison of atriopulmonary versus atrioventricular connections for modified Fontan/Kreutzer repair of tricuspid valve atresia. 7 Thorac Cardiovasc Surg 1986;92:1038-43.

11 Harrison DA, Liu P, Walters JE, et al. Cardiopulmonary function in adult patients late after Fontan repair. $₹ \mathrm{Am} \mathrm{Coll}$ Cardiol 1995;26:1016-21.

12 Yeh TJ, Willams WG, McCrindle BW, et al. Equivalent survival following cavopulmonary shunt: with or without the Fontan procedure. Eur 7 Cardiothorac Surg 1999;16:11116.

13 Gatzoulis MA, Hechter S, Siu SC, et al. Outpatient clinics for adults with congenital heart disease: increasing workload and evolving patterns of referral. Heart 1999;81. $57-61$.

14 Weipert J, Koch W, Haehnel JC, et al. Exercise capacity and mid-term survival in patients with tricuspid atresia and complex congenital cardiac malformations after modified complex congenital cardiac malformations after modified 80 .

15 Chua TP, Iserin L, Somerville J, et al. Effects of chronic hypoxemia on chemosensitivity in patients with univentricular heart. 7 Am Coll Cardiol 1997;30:1827-34.

16 DeLeon SY, Ilbawi MN, Idriss FS, et al. Persistent low cardiac output after the Fontan operation. Should takedown be considered? F Thorac Cardiovasc Surg 1986;92:402-5.

17 Troutman WB, Barstow TJ, Galindo AJ, et al. Abnorma dynamic cardiorespiratory responses to exercise in pediatric patients after Fontan procedure. $\mathcal{f} \mathrm{Am}$ Coll Cardiol 1998;31:668-73.

18 Nir A, Driscoll DJ, Mottram CD, et al. Cardiorespiratory response to exercise after the Fontan operation: a serial study. F Am Coll Cardiol 1993;22:216-20.
19 Gewillig MH, Lundstrom UR, Bull C, et al. Exercise responses in patients with congenital heart disease after Fontan repair: patterns and determinants of performance. f Am Coll Cardiol 1990;15:1424-32.

20 Zellers TM, Driscoll DJ, Mottram CD, et al. Exercise tolerance and cardiorespiratory response to exercise before and after the Fontan operation. Mayo Clin Proc 1989;64:148997.

21 Driscoll DJ, Feldt RH, Mottram CD, et al. Cardiorespiratory response to exercise after definitive repair of univentricular atrioventricular connection. Int $f$ Cardiol 1987;17:73-81.

22 Durongpisitkul K, Driscoll DJ, Mahoney DW, et al. Cardiorespiratory response to exercise after modified Fon$\tan$ operation: determinants of performance. $7 \mathrm{Am}$ Coll Cardiol 1997;29:785-90.

23 James FW, Blomqvist CG, Freed MD, et al. Standards for exercise testing in the pediatric age group. American Heart Association Council on Cardiovascular Disease in the Young. Ad hoc committee on exercise testing. Circulation 1982;66:1377-97.

24 American Thoracic Society. Lung function testing: selection of reference values and interpretive strategies. Am Rev Respir Dis 1991;99:408-15.

25 Jones NL. The interpretation of stage 1 exercise test results. In: Trumbold C, ed. Clinical exercise testing. Philadelphia: WB Saunders, 1988:158-85.

26 Percentile distributions of anthropometric and fitness variables by age (Canadians aged 10 and older). Ottawa: Canadian Fitness and Lifestyle Research Institute, 1999. Campbell Survey on Well-Being in Canada (1988)

27 Driscoll DJ, Durongpisitkul K. Exercise testing after the Fontan operation. Pediatr Cardiol 1998;20:57-9.

28 Driscoll DJ, Danielson GK, Puga FJ, et al. Exercise tolerance and cardiorespiratory response to exercise after the Fontan operation for tricuspid atresia or functional single ventricle. F Am Coll Cardiol 1986;7:1087-94.

29 Iserin L, Chua TP, Chambers J, et al. Dyspnoea and exercise intolerance during cardiopulmonary exercise testing in patients with univentricular heart. The effects of chronic hypoxaemia and Fontan procedure. Eur Heart $\mathcal{F}$ 1997;18: $1350-6$.

30 Bull C, de Leval MR, Stark J, et al. Use of a subpulmonary ventricular chamber in the Fontan circulation. 7 Thorac Cardiovasc Surg 1983;85:21-31.

31 Rhodes J, Garofano RP, Bowman FOJ, et al. Effect of right ventricular anatomy on the cardiopulmonary response to exercise. Implications for the Fontan procedure. Circulation 1990;81:1811-17. 